\title{
Michel Foucault e o feminismo: algumas ferramentas conceituais
}

\author{
Michel Foucault and feminism: some conceptual tools
}

Cesar Candiotto ${ }^{\mathrm{a}}$

\section{Resumo}

Neste artigo, indico como as análises de Michel Foucault podem fornecer algumas ferramentas conceituais para a crítica feminista. Inicio pela identificação dos processos de normalização que produzem o indivíduo moderno e como eles definem os papéis sociais a serem exercidos pelas mulheres. Aponto, em seguida, como seria possível caracterizar as resistências a esses processos de normalização disciplinar e governamental mediante noções, tais como contracondutas e atitude crítica. Sugiro, enfim, como o papel ocupado pelas mulheres na vida social e a função da maternidade que dela faz parte podem ser modificados.

Palavras-chave: Normalização. Feminismo. Contraconduta. Atitude crítica.

\section{Abstract}

In this article, I indicate how Michel Foucault's analysis can provide some conceptual tools for feminist criticism. I begin by identifying the normalization processes that produce the modern individual and how they define the social roles to be played by women. Then, I point out how it would be possible to characterize the resistance to these processes of disciplinary and governmental normalization through notions, such as counter-conducts and critical attitude. Finally, I suggest how the role played by women social life and the function of motherhood that is related to it can be modified.

Keywords: Normalization. Feminism. Counter-conduct. Critical attitude.

\footnotetext{
a Pontifícia Universidade Católica do Paraná (PUCPR), Curitiba, PR, Brasil. Doutor em Filosofia pela PUC-SP, e-mail: 


\section{Introdução}

Margaret A. McLaren (2016, p. 29) afirma, a propósito de Foucault, que "nenhum filósofo do século masculino, desde Marx, chamou tanta atenção das feministas".

Assim como as diferentes possibilidades de leitura do feminismo, as ideias de Foucault desafiam elementos centrais da filosofia tradicional, como a noção de sujeito, o lugar do saber, o exercício do poder. A potência de seu pensamento e seus desdobramentos são questionados ainda pelas teorias feministas quando o acusam de silenciar sobre a diferença sexual, além de não estabelecer distinções entre o corpo masculino e feminino em sua História da sexualidade. Destacam, além disso, a desconfiança foucaultiana em relação aos ideais iluministas, como o de emancipação, posição que parece invalidar as lutas das mulheres pela igualdade de condições e oportunidades.

É frequente a acusação de que Foucault não tem uma teoria normativa do poder, o que lhe impossibilitaria a fundamentação de uma política emancipatória ou libertária feminista. Ainda que problematize os processos de normalização que ocorrem nas práticas sociais, não oferece, porém, uma nova "proposta" teórica ou um novo projeto ético e político em seu lugar. E, assim, sua analítica do poder e sua genealogia do sujeito enfraqueceriam os ideais de emancipação e autonomia feministas.

Neste artigo me concentro nas posições de Foucault acerca da produção das normas sociais e como, diante delas, podem ser situadas as contracondutas e a atitude crítica. Argumento que seu pensamento não é em si mesmo antinormativo, sendo que seu problema é o universalismo e o essencialismo das estruturas normativas, muitas vezes sustentadas por um juízo a priori de seu valor tacitamente positivo.

Indico que as normas sociais tendem a se institucionalizar e a operar não somente como fatores integradores, mas também como ferramentas de controle dos corpos, de governo das condutas e da constituição de subjetividades sujeitadas. A análise genealógica das relações de poder suspeita da maneira como as normas sociais foram "naturalizadas" por processos 
históricos dos quais é possível identificar seu nascimento, suas transformações e seu modo de atuação.

Ainda que as normas sociais tenham um alcance muito maior que as leis, elas não são eternas. Ao contrário das leis, cuja coerção é externa e não exige uma adesão subjetiva, as normas e regras operam somente se forem internalizadas pelos indivíduos. Nesse sentido, as coerções baseadas na vigilância e na punição dos corpos, observadas especialmente nas estruturas espaciais da tecnologia de poder disciplinar, seriam inoperantes sem a constituição de uma psiqué.

As normas sociais não são naturais e, muito menos, universais. Cada sociedade tem seu regime de verdade, seu conjunto de normas a partir dos quais procura-se controlar a multiplicidade dos corpos individuais, regular a diversidade da vida e sua circulação, governar a conduta dos indivíduos e atuar na constituição de sua subjetividade. As possibilidades de resistências a esse controle, regulação, governo e constituição somente podem ser locais e específicas e visam expandir-se, sem jamais adquirir um caráter uniforme.

Como Foucault não desdobrou essa relação com as normas sociais na esfera das relações entre o masculino e o feminino, ou no terreno da divisão sexual explorado pelas análises feministas, tentarei, na medida do possível, demonstrar que, se o conteúdo de suas pesquisas pode ser legitimamente objeto de crítica por parte dos diversos feminismos, já as estratégias metodológicas e os conceitos que ele movimenta podem funcionar como uma "caixa de ferramentas" válida para o pensamento feminista e suas lutas.

\section{A crítica da função normalizadora das normas}

Os movimentos feministas, já no final do século XIX, apontam que as normas sociais e culturais de matriz patriarcal que legitimam a dominação sobre as mulheres podem ser postas a nu, modificadas e, até mesmo, desobedecidas. Estes movimentos progressivamente fazem um diagnóstico de seu presente e, através de estudos históricos, culturais e políticos demonstram que as normas de teor masculino que operam como padrão nas diferentes dimensões da vida social e política são produzidas historicamente. 
Eles ressaltam que as narrativas bíblicas da criação, as definições filosóficas da mulher como um "macho falho" ou as narrativas românticas que docilizam um suposto ser feminino servem para produzir uma regulação da vida cultural, social e política pelos valores masculinos, dando origem ao que se entende como a constituição do poder patriarcal.

Em relação às mulheres, o poder da norma opera de diferentes maneiras, especialmente pela sua distribuição espacial. Se os processos de normalização, que ainda são os nossos, derivam das práticas institucionais e disciplinares modernas cujo fim precípuo é a produção de um corpo útil para o trabalho e uma vontade dócil e obediente, já as mulheres foram constituídas como sujeitos na modernidade por uma dupla espacialização: primeiro, a utilização de seu corpo e a docilização de sua vontade no espaço privado da casa, no escondimento do lar, nos afazeres domésticos e na criação dos filhos. Em seguida, a introdução das mulheres nas fábricas no século XIX, quando seus corpos e sua força de trabalho também são utilizados para a produção da maisvalia e o acúmulo do capital.

Com efeito, o duplo confinamento, na casa e na fábrica, torna as mulheres peças centrais do aparato produtivo e reprodutivo do capitalismo moderno. Assim é que boa parte dos movimentos feministas denuncia a dupla exploração do corpo das mulheres que as análises de Marx não teriam percebido, porque centradas somente na luta de classes e focadas nas relações fabris entre capital e trabalho. Assim, o trabalho não pago e não reconhecido que as mulheres exercem no âmbito doméstico serve para que o companheiro ou marido possa descansar e repor sua força de trabalho. Todavia, é justamente neste ponto que uma análise exclusivamente economicista sobre a normalização dos corpos das mulheres mostra-se insuficiente.

A esse respeito, a analítica do poder de Foucault pode contribuir, de alguma maneira. Ele entende que uma análise complexa do poder é irredutível à luta de classes entre dominantes e dominados, exploradores e explorados. Um dos problemas do marxismo, segundo Foucault, é que ele minimiza a importância das lutas em proveito da análise da classe, mascarando outras formas de lutas que Ihe são transversais ou, até mesmo, independentes das divisões de classe. 
Certos feminismos marxistas correm o risco de cair nesse perigo: eles designam a posição das mulheres como uma "classe sexual" cuja subordinação é justificada economicamente pela dinâmica do modo de produção do capital. Eles concebem ainda que a dominação das mulheres pelos homens e toda forma de sexismo tem sua raiz no sistema de propriedade privada, o mesmo que, pelo casamento, concebe as mulheres como propriedade dos pais e, em seguida, de seus maridos.

Michel Foucault, pelo contrário, entende que o poder não é simplesmente uma coisa que alguém simplesmente cede e transfere; ele não é uma propriedade que alguém tem, ao mesmo tempo que alguém não a tem. Pensar que na raiz das relações de poder encontra-se a propriedade privada não seria totalmente inadequado, porém seria insuficiente para tratar da complexidade destas relações.

O marxismo deduz as relações de poder de sua determinação econômica em última instância, de maneira que outras formas de desigualdade, discriminação, dominação e opressão no interior da família, dos sistemas educacionais e da religião são tidos como efeitos superestruturais da exploração da força de trabalho não paga, responsável pelo acúmulo do capital no nível infraestrutural. Também neste ponto, o pensamento de Foucault toma outro rumo. A desigualdade econômica não pode ser considerada a única matriz explicativa de todas as outras formas de desigualdade e de dominação.

Foucault sustenta que na modernidade há uma isomorfia entre a formafábrica, a forma-prisão, a forma-escola, a forma-Igreja e assim por diante, que se situam em um plano de imanência e encarregam-se da produção de uma sociedade normalizadora e disciplinadora. Entretanto, faltou a Foucault tratar da forma-vida doméstica, que sequestra a vida das mulheres no confinamento do lar, o que não deixa de ser uma prática institucional em sua forma correlacionada a todas as outras, que opera, porém, mediante a criação de outras divisões e produções de subjetividade.

Se voltarmos ao caso da exploração do corpo das mulheres no espaço doméstico para que os homens possam repousar e repor sua força de trabalho, vislumbramos que nele atua outra forma de divisão, agora baseada no sistema 
sexo/gênero. Se o poder não convém ser pensado somente pela luta de classes entre exploradores e explorados, estendendo-se também à relação entre forças em outros âmbitos das práticas sociais, então ele pode ser associado às "relações" de gênero. Dessa maneira, as mulheres são levadas a interiorizar sua dedicação aos filhos e afazeres domésticos como algo inerente a uma maneira de ser e viver considerada feminina, e da qual os homens não precisam ocupar-se.

As análises de Foucault não buscam integrar correntes de pensamento, mas sim problematizar diferentes práticas sociais. Elas evidenciam que o poder opera de distintas formas no conjunto do tecido social, sendo que as lutas acerca da eliminação da desigualdade econômica estão entrelaçadas às lutas contra todas as formas de discriminação, como as de gênero. As relações de poder, evidenciadas como jogo de forças entre gêneros, produzem sujeitos sujeitados nas diferentes classes sociais e, até mesmo, para além delas. Assim, uma mulher pode sofrer discriminação de gênero, ainda que pertença economicamente à classe dominante.

Os processos de normalização que universalizam o padrão masculino como parâmetro das relações sociais não mudaram a mentalidade de muitos homens no recinto doméstico, espaço em relação ao qual as mulheres são consideradas ainda as únicas responsáveis. Esses processos igualmente persistem no espaço público e precisam avançar muito nas relações formais de trabalho, nos quais força física, características biológicas e traços psicológicos atribuídos às mulheres dificultam seu acesso a determinados cargos e funções. Mantêm-se a mentalidade segundo a qual as mulheres têm aptidão natural para cuidar dos filhos e ocupar-se dos afazeres domésticos, enquanto no espaço público e laboral elas precisam incorporar maneiras de ser e pensar masculinos, caso queiram ser razoavelmente bem-sucedidas. Portanto, a distribuição espacial dos corpos e seu controle é um mecanismo decisivo dos processos de normalização que definem um modo de ser feminino em função do lugar ocupado nos seus papéis e funções sociais. 


\section{A genealogia como crítica dos processos de normalização}

De maneira geral, considera-se que as normas sociais são boas e positivas pois servem para regular o comportamento e propiciar a interação social. Alguém poderia pensar que, ao contrário, para Foucault, estas normas e códigos são todos negativos e ruins porque estabelecem sistemas de exclusão e marginalização. De fato, quando se lê Vigiar e punir (1975) e a descrição da ortopedia moral da sociedade disciplinar como uma sociedade de normas (MACHEREY, 2014), tem-se a impressão de que os processos de normalização modernos produzem somente sujeições, sem a possibilidade de resistências.

Em relação às normas, creio que o critério utilizado por Foucault não seja objetivá-las como negativas ou más, sem mais. Tampouco significa condescender com a imaginação de que sejam boas e positivas. Algumas normas sociais ou códigos morais podem ser menos normalizadores que outros, no sentido de que deixam maior margem para maneiras diferenciais de segui-las; ou não são excludentes, quando se deixa de cumpri-las. Entretanto, a tendência é que as práticas sociais e institucionais tendam à normalização pois fabricam um padrão de comportamento para, a partir dele, objetivar e excluir comportamentos desviantes e anormais. Portanto, deve-se suspeitar das normas sociais quando estão a serviço de dominações políticas, fundamentalismos religiosos e exploração econômica.

Sempre é possível limitar e, até mesmo, inibir a tendência normalizadora das normas. Neste caso, a suspeita e a desconfiança em relação às normas não desanda necessariamente no niilismo ou anarquismo, mas em direção a uma ação política sempre local e específica, ainda que ela possa ser conjugada com outras formas de ação política. O problema de Foucault é quando as normas sociais, historicamente produzidas, são justificadas como se fossem universais, pautadas em um valor prévio positivo e inquestionável, operando como uma verdade incontestável.

Se em relação às normas, um dos critérios de Foucault não consista em rejeitá-las porque são más, ou aprová-las porque são boas, assim também outro critério não seria delimitar se elas são verdadeiras ou falsas, pautado em 
uma pré-concepção de verdade objetiva. A genealogia busca justamente investigar as condições históricas segundo as quais emergem os juízos de verdade e falsidade nos discursos que se erigem como normalizadores, e especialmente quando estes juízos atuam na constituição dos sujeitos.

O conceito de poder-saber de Foucault é central neste ponto. Para se reproduzirem, as relações de poder operam pela produção de verdades; e, inversamente, para que um saber entre na ordem do discurso legítimo ele precisa de um suplemento de poder. Desta maneira, Foucault postula que as verdades circulam no domínio das ciências humanas e sociais, mas nega que neste domínio elas sejam universalmente válidas e neutras, ou seja, independentes de sua produção histórica e localizadas fora das relações de poder-saber.

A genealogia constata que o critério objetivo da verdade ou do erro das ciências rígidas não pode ser simplesmente transferido para as ciências humanas e sociais. Até mesmo as verdades consideradas científicas, biológica ou neurologicamente constatáveis, utilizam-se de um suplemento de poder, que enquadram seu discurso no interior de uma norma. Assim a teoria evolucionista da seleção natural de Darwin foi utilizada por Herbert Spencer para a proposição de uma normalização segundo a qual nas relações sociais sobrevivem os mais aptos e definham os menos adaptados.

Esse argumento poderia ser utilizado para afirmar que a desigualdade das mulheres em relação aos homens no mercado de trabalho não é o efeito de uma relação de poder, mas o desdobramento de uma constatação científica. De igual maneira, o significativo conhecimento médico e psicológico da sexualidade tem sido acompanhado paradoxalmente da intensificação do controle social da sexualidade. Foucault não nega que certas normas derivem das descobertas científicas, mas coloca sob vigilância a função normalizadora dessas normas na constituição dos sujeitos, sempre que elas pretendem assumir um valor universal, ao mesmo tempo moral e epistemológico.

Se ele procura diagnosticar a formação histórica da função normalizadora das normas sociais e códigos morais, ou seja, seu papel no controle e regulação da conduta baseado em sua justificação de neutralidade, universalidade e, até mesmo, de sua origem divina, convém perguntar então se é possível derivar de sua análise uma posição crítica em relação às normas, 
já que parece rejeitar qualquer justificativa de ação baseada em uma justiça universal, em um conceito de natureza humana ou, até mesmo, em direitos tidos como humanos e universais.

Sustento que a análise de Foucault permite a realização de uma postura crítica válida para os movimentos feministas, sem a necessidade da postulação filosófica de uma verdade universal e transcendental. Se os processos de normalização são contingentes e históricos, a crítica social, assim como as resistências, não precisam estar baseados em soluções abstratas e universalizantes.

Esta posição de Foucault está muito próxima dos feminismos atuais quando estes desconfiam dos projetos neutros relacionados ao gênero. Sempre que projetos universais pretendem ser neutros e objetivos, têm como modelo o paradigma masculino. Por isso, as intervenções políticas e sociais precisariam prestar atenção às situações específicas que se desdobram das experiências próprias das mulheres. Não das mulheres como uma categoria uniforme determinada pela condição biológica, como se a portadora do sexo feminino já carregasse em si mesma a potencialidade de uma experiência política feminina.

Como advertem boa parte dos feminismos atuais, é muito difícil evocar uma experiência feminina dissociada das diferenças étnicas, culturais, de classe social e de orientação sexual. Mais do que falar da experiência feminina, melhor seria postular diferentes experimentações contingentes e históricas, irredutíveis a qualquer forma de essencialismo.

Portanto, a genealogia apresenta-se como uma crítica histórico-prática da atuação da função normalizadora da norma na constituição de sujeitos sujeitados e obedientes, como é o caso de mulheres subordinadas e docilizadas. Se Foucault não coloca em suspeição as normas sociais em si mesmas, mas sim sua função normalizadora, caberia saber então quais os desdobramentos dessa crítica histórico-prática em seu pensamento e como eles podem auxiliar para uma avaliação menos negativa de suas pesquisas em relação aos feminismos. 


\section{As contracondutas feministas}

Sobre a normalização que naturaliza o controle dos corpos, o governo das condutas e a subjetividade das mulheres, Foucault não tem uma análise específica. Em compensação, ao menos duas ferramentas conceituais podem nos auxiliar a esse respeito: contraconduta e atitude crítica.

Nenhuma delas propõe a subversão das normas existentes ou a desobediência às regras morais como única forma de resistência ou emancipação possível. Como há uma imanência entre relações de poder e resistências na concepção foucaultiana de poder, as resistências não eliminam os processos de normalização, mas antes servem para desviá-lo, dobrá-lo, freálo ou escapar dele. Isso não quer dizer, além disso, que o poder seja necessário ou inevitável. Quem afirma não ser possível escapar do poder porque está dentro dele, é porque não o entende em seu caráter eminentemente relacional e reversível.

Desde 1978, Foucault posiciona o poder na sua designação de governamentalidade ou artes de governo, indissociável da liberdade e das resistências. Dentre as diversas concepções dessa ferramenta conceitual, a governamentalidade designa os “jogos estratégicos entre liberdades - jogos estratégicos que fazem que uns tentem determinar a conduta dos outros, aos quais os outros respondem tentando não deixar determinar sua conduta ou tentando determinar, em retorno, a conduta dos outros". (FOUCAULT, 2001, p. 1547).

Analisadas por Foucault no curso de 1978, Segurança, território, população (2004), as contracondutas fazem parte deste jogo estratégico entre liberdades e estão diretamente articuladas às lutas contra a governamentalização da conduta e seu efeito maior, que é a sujeição da subjetividade. ${ }^{1}$ Foucault considera que desde o nascimento do poder pastoral no Ocidente cristão do século IV, observa-se a tentativa de governo das condutas por meio da exigência da obediência autofinalizada e da verbalização

\footnotetext{
1 Para uma análise das contracondutas feministas diante de uma maneira específica de governamentalidade, que é a neoliberal, remeto-me ao livro organizado por Mauricio Pelegrini e Margareth Rago. Neoliberalismo, feminismos e contracondutas (2019).
} 
de si mesmo. Em relação ao governo pastoral das almas, as contracondutas não constituem a negação do governo, mas a instauração de outras técnicas, de outras artes de governar. É o caso do movimento da mística cristã medieval e sua resistência à mediação eclesiástica e seu poder pastoral. ${ }^{2}$

Na pastoral [...], era necessário que houvesse direção da alma individual pelo pastor, e no fundo nenhuma comunicação da alma com Deus poderia ser feita sem ser relegada e controlada pelo pastor. O pastorado era o canal que se estendia do fiel a Deus. É claro que, na mística, você tem uma comunicação imediata que pode ser na forma do diálogo entre Deus e a alma, na forma do chamado e da resposta, na forma da declaração do amor de Deus para a alma, da alma para Deus. [....]. Você tem também uma comunicação pelo silêncio. Você tem também a comunicação pelo corpo-a-corpo, quando o corpo do místico experimenta efetivamente a presença, a presença intensa do corpo do próprio Cristo. Portanto aí também, vocês vêm como a mística está distante da pastoral. (FOUCAULT, 2004, p. 216-217)

Se consideramos o número expressivo de mulheres místicas na Igreja no decurso de sua história, podemos ver que esta prática se desvia tanto da obediência incondicional ao pastor quanto da exigência de verbalização constante de atos, pensamentos e desejos que as mulheres, especialmente no interior dos conventos, deveriam expressar ao pastor. A mística é uma arte de governar que não nega o pastorado, mas dele se desvia sempre quando prevalece sua ambição de controlar e normalizar a vida de todos os fiéis, especialmente a das mulheres.

Desde a época da emergência do poder pastoral, no século IV d.C., presencia-se com certa recorrência a tentativa de normalização de condutas das mulheres por parte de pastores religiosos. E ainda em nossa época, não é incomum que outros pastores exijam das mulheres uma discursividade sobre si mesmas, tornando estes pastores agentes de novas modalidades de obediência e submissão religiosa (e, até mesmo, política).

\footnotetext{
2 Foucault cita, a esse respeito, as "revoltas de conduta" relacionadas ao estatuto das mulheres na sociedade civil ou religiosa, empreendidas principalmente nos conventos femininos a partir do século XII, como no movimento Nonnenmystik renano. Igualmente é mencionado o movimento das mulheres profetizas na Idade Média, especialmente Jeanne Debenton, Marguerite Porete; no século XVI, na Espanha são nomeadas Isabel de la Cruz; na França, Armelle Nicolas e Marie des Vallées, Madame Acarie.
} 
É o momento de se perguntar até que ponto as mulheres poderiam ser as agentes privilegiadas na constituição de uma nova mística capaz de dobrar formas de viver religiosas e pretensos pastores que fazem uso da mediação do dinheiro e do poder para se relacionar com Deus e dele obter algum favor. Além disso, seria necessário investigar até que ponto a noção de contraconduta proposta por Foucault é uma ferramenta conceitual suficiente para pensar as resistências ao poder pastoral.

\section{A atitude crítica feminista}

A segunda ferramenta conceitual que pode ser mobilizada como forma de resistência é a de atitude crítica. Apesar de Foucault ser um crítico da Modernidade, especialmente da ideia de sujeito transcendental embasadas pelo kantismo e neokantismo, não significa que ele seja considerado um niilista sem qualquer sustentáculo para apoiar sua crítica social.

A crítica que Foucault sustenta não parte de uma razão pura a priori, mas de acontecimentos históricos de resistência às diferentes maneiras de governar no Ocidente. Trata-se de uma crítica ético-política pela qual o sujeito é constituído historicamente no interior de um jogo governamental.

Na conferência de 1978, Qu'est-ce que la critique. Critique et Aufklärung, ele identifica, desde os séculos XV e XVI, no contexto da crítica religiosa e política, o surgimento, na Europa ocidental, de uma atitude crítica, que, de maneira genérica, pode ser designada como "uma maneira de pensar, de dizer, igualmente de agir, uma relação com o que existe, com o que sabemos e fazemos, uma relação com a sociedade, com a cultura, com os demais [...]" (FOUCAULT, 2015, p. 34).

A atitude crítica apresenta-se como múltipla, dispersa e instrumental atuando em função de domínios específicos, tais como na filosofia, na ciência, na política, na moral, no direito e na literatura. Especificamente considerada, ela refere-se à questão recorrente do século XVI: "como não ser governado desse modo, por isso, em nome desses princípios, em vista de tais objetivos e por meio de tais procedimentos, não assim, não para isso, não por eles" (FOUCAULT, 2015, p. 37). A atitude crítica evidencia o limite das artes de governar impelindo sua modificação, embora jamais seu desaparecimento. 
Exemplos da "arte de não ser governado de uma determinada maneira" (FOUCAULT, 2015, p. 37) são encontrados nos domínios religioso, jurídico e científico.

No domínio da religião, quando o governo dos homens é predominantemente espiritual ou uma prática religiosa ligada ao Magistério eclesiástico e ao cânon da Escritura, a recusa de ser governado dessa ou daquela maneira envolve a atitude de releitura das Escrituras de modo a estabelecer outra relação daquela normalmente mediada pelo poder pastoral. Essa arte de não ser governado por determinados agentes é típica do protestantismo do século XVI. Não ser governado supõe fazer a própria Escritura falar ao ser humano, de modo a poder interpretar subjetivamente o que nela está escrito, sem necessidade absoluta da intermediação da instituição eclesiástica.

O pastor pode comentar, explicar o que é obscuro, designar o que é importante, mas, de qualquer modo, isso será feito para que o leitor possa ler a própria Escritura. E o ato de leitura é um ato espiritual que coloca o fiel em presença da palavra de Deus e que encontra, em consequência, nessa iluminação interior, sua lei e garantia. (FOUCAULT, 2004, p. 217).

Interpretar livremente a Bíblia constitui um modo fundamental de limitar a atuação do poder pastoral no espectro do século XVI. Esse gesto questiona a univocidade da interpretação eclesial ao perguntar pela autenticidade e veracidade das Escrituras e de seu cânon. Portanto, uma crítica historicamente bíblica em face da autoridade eclesiástica.

Para além de Foucault, podemos dizer que nas Comunidades Eclesiais de Base no Brasil e na América Latina, e, depois, nas diferentes perspectivas da teologia feminista, as mulheres teólogas tentaram inaugurar uma nova hermenêutica dos textos bíblicos sustentadas em sua própria experiência de vida e de fé. Esta experiência não deixa de ser uma arte da indocilidade refletida, uma arte de não ser governadas por uma interpretação que muitas vezes normaliza sua subordinação aos homens pela definição de seus papéis e funções na sociedade e na vida doméstica. Não se trata também de negar absolutamente o poder pastoral, mas de rejeitá-lo sempre quando ele faz uso 
de uma hermenêutica que naturaliza o feminino como o lugar da desconfiança, do pecado e do mal, para não dizer, da subordinação e sujeição.

No domínio jurídico, não querer ser governado desse ou daquele modo materializa-se ainda pela não aceitação passiva de certas leis, por considerá-las injustas, quando ignoram as leis derivadas do direito natural. $O$ estudo do direito natural no século XVI cumpre com sua função crítica diante do poder despótico e se estende até hoje. Por conseguinte, como desdobramento da questão de como não ser governado, o direito natural atuou como "princípio" de "limitação" do direito de governar (FOUCAULT, 2004, p. 10). Trata-se de uma crítica jurídica diante das leis positivas.

Para além de Foucault, pode-se dizer que, de semelhante maneira, a atitude crítica pode ser materializada pela tentativa de não se deixar governar por maridos e pais, sempre que esse governo for abusivo e despótico. Não podemos esquecer que o termo despotés, na língua grega, tem sua origem de aplicação no âmbito do governo econômico doméstico, em referência ao direito de vida e morte que o pai de família usufruía em relação à sua mulher e seus filhos.

No século XX, a atitude crítica desdobrou-se na luta histórico-prática em torno dos direitos humanos das mulheres diante de leis injustas e abusivas. $O$ alcance da sanção jurídica contra toda forma de violência contra a mulher, inclusive o feminicídio, adquiriu especificidade no Brasil pela Lei 11. 340/2006, denominada Lei Maria da Penha, invocada não mais pelo argumento dos direitos naturais, mas a partir dos direitos humanos das mulheres contra qualquer violência e discriminação. (Cf. SOUZA CANDIOTTO, 2020).

Apesar da evolução da normatização contra estas formas de violência, permanece a função normalizadora de certos códigos pautada em valores masculinos que perpetuam a condenação moral das mulheres, em caso de adultério, e que, como consequência dessa moralidade, "perdoam" os homens que recorrem ao feminicídio. $O$ número altíssimo dessa tipificação de assassinatos das mulheres no Brasil demonstra que esse aspecto da atitude crítica precisa ser ainda muito aperfeiçoado, a começar pela coibição de toda forma de violência doméstica contra as mulheres.

Finalmente no domínio científico, não querer ser governado dessa ou daquela maneira envolve também a renúncia em aceitar incondicionalmente 
algo como verdadeiro porque a autoridade diz que é verdadeiro. Já no século $\mathrm{XVI}$, o discurso da autoridade merece aceitação somente se houver boas razões para ser aceito e se o indivíduo estiver convicto de que o que lhe é proposto, de fato, tem um valor de verdade. Personagens como Giordano Bruno e Galileu Galilei, que eram ao mesmo tempo religiosos e cientistas, mostraram que o ponto de sustentação da crítica consiste em opor a certeza que advém do conhecimento científico ante o abuso que decorria da autoridade eclesiástica. É conhecido o confronto entre, de um lado, a verdade da autoridade eclesiástica medieval, apoiada na cosmologia aristotélica e sua justificação hierárquica dos estamentos sociais e da origem divina do poder; e, de outro, as descobertas das ciências modernas, que indicam um mundo infinito e uniforme alimentando a aspiração para uma sociedade pautada pelos ideais de igualdade e liberdade.

Os movimentos feministas podem argumentar que a ciência moderna, ao mesmo tempo que representou uma crítica contumaz ao poder eclesiástico, manteve, na sua justificativa e atuação, a mesma mentalidade patriarcal que resultou na espoliação dos recursos naturais pela sua associação à fertilidade feminina. Além de denunciar o patriarcado como um constructo normalizador inerente ao poder pastoral religioso, os movimentos feministas não deixaram de reativar saberes sujeitados pela própria ordem do discurso inerente à ciência moderna.

Não é incomum associar a formação da ciência moderna e seus desdobramentos tecnocráticos a uma nova religião sem Deus, nas sendas deixadas por Augusto Comte. Em certo aspecto, as ciências modernas não se emanciparam totalmente do autoritarismo eclesiástico medieval, à medida em que reconfiguraram sua face patriarcal pelo acesso desigual das mulheres ao mundo da ciência. Além disso, a divisão entre os saberes também é um componente de discriminação sexista. Vige o preconceito de que o terreno das ciências rígidas ou duras é um espaço masculino, enquanto que os saberes pedagógicos e sua profissionalização na educação infantil é um espaço mais feminino.

Dessa maneira, desde o século XVI a atitude crítica em suas dimensões religiosa, política e científica desemboca no questionamento do magistério por 
meio da volta às Escrituras, na não-aceitação incondicional da lei mediante o estudo do direito natural e na relativização do autoritarismo clerical a partir de argumentos oriundos das ciências.

Em sua conferência de 1978, acima aludida, a atitude crítica não é considerada um desdobramento do lluminismo do século XVIII, mas algo que o precede e o atravessa, sem se identificar totalmente com ele. Essa atitude preserva marcas contemporâneos nos movimentos de mulheres, as quais mudaram significativamente o terreno religioso, político e científico pela constituição de uma arte de não ser governadas de qualquer maneira e por quaisquer agentes.

No entanto, ao mesmo tempo em que o lluminismo reativa a atitude crítica, ele instaura uma filosofia da história pautada na ideia de progresso ininterrupto da razão. Foucault sempre desconfiou do otimismo de uma emancipação que retrocede jamais. A atitude crítica, neste sentido, toma distância da crença positivista segundo a qual as conquistas políticas históricas das mulheres jamais viessem a retroceder. $\mathrm{Na}$ verdade, as relações de força podem ser alteradas, independentemente das conquistas adquiridas. Os movimentos de mulheres por emancipação não podem ser pensados somente no interior desse suposto progresso.

Diversas racionalidades perpassam o lluminismo, a atitude crítica sendo uma delas. Ao mesmo tempo em que Foucault extrai da Aufklärung problematizada por Kant a possibilidade do diagnóstico do presente e a considera uma das reconfigurações modernas da atitude crítica, também adverte sobre o próprio recuo de Kant, quando este submete a Aufklärung à crítica transcendental. Ora, como retomarei mais adiante, pensar a emancipação das mulheres pela sua fundamentação na autonomia transcendental do sujeito moral engessaria suas próprias lutas, além de desidratar o potencial da crítica como atitude histórica e política diante das tentativas de governo das condutas das mulheres.

A atitude crítica pode ser reativada continuamente por parte dos movimentos feministas como um dispositivo de luta e resistência, de maneira que tudo aquilo que foi alcançado não seja repentinamente destruído. A arte de não serem governadas de determinada maneira e por determinados agentes (tutores, pais, maridos, patrões, companheiros); a resistência em não 
se dobrarem, aqui e agora, aos processos que procuram sujeitar suas vontades; a insubmissão voluntária diante das tentativas explícitas e veladas de governo de suas condutas pela normalização de suas maneiras de pensar e agir poderiam caracterizar uma atitude crítica feminista.

Um exemplo contemporâneo de atitude crítica, como desejo de não serem governadas de uma certa maneira por parte das mulheres, advém da experiência da maternidade. Ele poderia ser mobilizado para mostrar, por exemplo, até que ponto a escolha pela maternidade significaria condescender com a adesão servil à maneira de governar patriarcal e seus tentáculos contemporâneos. Diante dos processos de normalização que elevaram a possibilidade biológica da maternidade às normas sociais e culturais objetivadas como uma espécie de ser “feminino", a resistência não consistiria necessariamente na recusa da maternidade como contrapartida da governamentalização masculina, mas antes na tentativa de desvio de seus efeitos sociais e culturais de normalização, como os que decorrem de sua associação ao confinamento doméstico, à subordinação aos maridos e assim por diante.

Nesse sentido, o movimento das Mães da Praça de Maio, de Buenos Aires, trazido à baila como exemplo de resistência por Margaret A. McLaren, no livro com o qual dou início a este artigo, demonstra como a maternidade pode ser considerada um dispositivo que opera na contramão do confinamento doméstico das mulheres.

Muitas crianças, filhos e filhas de pessoas presas, torturadas e mortas na ditadura argentina nos anos setenta e oitenta foram "doados" a famílias favoráveis ao regime de exceção ou, até mesmo, às famílias dos próprios torturadores. Como a discriminação de gênero ainda era muito contundente na Argentina desta época, convencionou-se que seria função das mães buscarem seus filhos desaparecidos, pois os pais precisavam trabalhar. Se a busca inicialmente era individual e tropeçava na burocracia do governo, já as longas esperas decorrentes dessa burocracia foram o ensejo para que elas começassem a partilhar suas histórias de vida, a reunir-se em escolas e igrejas e, desde 30 de abril de 1977, a realizarem reuniões e passeatas na Praça de Maio. 
Como sublinha Marguerite Guzman Bouvard, no livro Revolutioning Motherhood: The Mother of the Plaza de Mayo (1994, p. 65), citada por McLaren (2016, p. 72-73):

Quando elas iniciaram a frenética busca por seus filhos, eram essencialmente donas de casa, felizes com sua absorção na família e nos cuidados com o lar, expressando pouco interesse no mundo lá fora. Elas foram socializadas nesses papéis por uma sociedade argentina tradicional que mantém o homem como a figura dominante, o único participante da vida pública e o incontroverso chefe de casa.

A passagem indica como é possível dobrar a normalização de uma regra, subvertendo-a pela atitude crítica. O movimento das mães da Praça de Maio foi utilizado como instrumento comum de interação entre as mães - agora avós - de desaparecidos políticos de distintas classes sociais, religiões e procedências, dando-lhe uma dimensão pública de resistência política de inegável importância. Desta feita, mobilizar a função materna como um veículo de mobilização política enseja outra relação consigo mesmo e com os outros, diante de um modelo de governamentalização patriarcal.

\section{Considerações finais}

A atitude crítica das mulheres em relação à normalização de seus corpos e à governamentalização de suas condutas pode chegar a ter como efeito a transformação, não somente de si mesmas, mas também dos agentes masculinos que estão acostumados a vigiar e punir seus corpos, a regular e governar suas condutas.

Creio que esse efeito esperado pela atitude crítica feminista poderia circunscrever atualmente aquilo denominado como "lugar de fala". Este lugar é evocado como condição imprescindível para a legitimidade política das contracondutas e atitude crítica da governamentalização das condutas e a normalização dos corpos das mulheres. Por certo, é um pressuposto prático inquestionável identificar na experiência das mulheres governadas por diferentes agentes o lugar e ponto de partida privilegiado de alteração de qualquer jogo governamental. No âmbito desse jogo, a arte de não ser 
governadas por parte das mulheres é capaz de alterar a posição e função ocupada por aqueles que pretendem governá-las.

No entanto, o problema é que o "lugar de fala" normalmente é situado teoricamente fora desse jogo, chancelando previamente um discurso baseado somente em uma experiência feminina, ou no fato de ser mulher. Esse possível engessamento quase metafísico do lugar de fala pode correr o risco de desembocar em uma circularidade identitária que enfraquece a transversalidade e a pluralidade das lutas políticas das mulheres.

Se situado da perspectiva do jogo governamental, Foucault não remeteria o "lugar de fala" somente a "quem fala?", no caso de que somente mulheres poderiam exercer a atitude crítica diante da governamentalização patriarcal; ou que somente elas teriam a legitimação prévia e única para o exercício da atitude crítica neste âmbito. O movimento é inverso: a legitimidade de quem fala depende de seu lugar - de sua posição e função - no jogo governamental, no caso, o lugar que as mulheres ocupam nas relações de poder. Se a experiência das mulheres jamais deixa de ser importante, no interior do jogo governamental ela adquire um contorno ético-político enquanto atitude crítica, como no caso das lutas de resistência diante das tentativas de governamentalização da conduta das mulheres. No âmbito deste jogo, pode-se encontrar outras mulheres que não ocupam este mesmo lugar e posição nas relações de poder, somando-se, muitas vezes, aos "agentes" que buscam normalizar e governar suas condutas e disciplinar seus corpos.

Considerando a posição e a função que normalmente ocupam nas relações sociais e políticas, jamais os homens tomarão a iniciativa de se liberarem da imagem que têm de si mesmos como agentes do governo sobre as mulheres. Justamente neste ponto é que reside a importante da atitude crítica dos movimentos feministas e suas conquistas sociais e políticas. São as mulheres e seus movimentos que conduziram à desestabilização sem fim destes papéis e funções exercidas pelos homens na sociedade. Na posição de governadas é que as mulheres feministas criaram as condições históricas para que os homens pudessem dessubjetivar sua imagem de governantes da conduta feminina. Em síntese, são os próprios movimentos feministas e suas conquistas que permitiram a alguns homens ocuparem algum "lugar de fala", 
jamais para falar em nome das mulheres, mas na companhia delas, como seus parceiros de uma luta comum.

\section{Referências}

FOUCAULT, M. Surveiller et punir. Naissance de la prison. Paris: Gallimard, 1975. (Coll. Bibliothèque des Histoires).

FOUCAULT, M. Le Sujet et le pouvoir. In: FOUCAULT, M. Dits et écrits, II. 1976-1988. Paris: Quarto/Gallimard, 2001a. p. 1041-1062.

FOUCAULT, M. Qu'est-ce que la critique? In: FOUCAULT, M. Qu'est-ce que la critique? Suivi de la culture de soi. Org. de Henri-Paul Fruchaud et Daniele Lorenzini. Paris: Vrin, 2015.

FOUCAULT, M. Sécurité, territoire, population. Cours au Collège de France,1977-1978. Édition établie par François Ewald et Alessandro Fontana, par Michel Senellart. Paris: Gallimard/ Seuil, 2004. (Coll. Hautes études).

FOUCAULT, M. L'Herméneutique du sujet. Cours au Collège de France, 1981-1982. Édition établie par François Ewald et Alessandro Fontana, par Frédéric Gros, Paris: Seuil/Gallimard, 2001b. (Coll. Hautes études).

MACHEREY, P. Le sujet et les normes. Paris: Éditions Amsterdam, 2014.

MCLAREN, M. A. Foucault, Feminismo e Subjetividade. Trad. Newton Milanez. São Paulo: Intermeios, 2016.

RAGO, M.; PELEGRINI, M. Neoliberalismo, Feminismos e Contracondutas: perspectivas foucaultianas. São Paulo: Intermeios, 2019.

SOUZA CANDIOTTO, J. de F. Direitos humanos, teologia e relações de gênero. Estudos Teológicos, São Leopoldo, v. 60, n. 1, p. 55-68, jan./jun. 2020. 